\title{
Construing Professional Knowledge of Secondary School Teachers of Mathematics: A Historical Perspective
}

\author{
José Manuel Matos ${ }^{1,2 \star}$
}

${ }^{1}$ Universidade Federal de Juiz de Fora, BRAZIL

${ }^{2}$ Universidade Nova de Lisboa, PORTUGAL

*Corresponding Author: jmm@fct.unl.pt

Citation: Matos, J. M. (2020). Construing Professional Knowledge of Secondary School Teachers of Mathematics: A Historical Perspective. Pedagogical Research, 5(3), em0058. https://doi.org/10.29333/pr/7898

\begin{tabular}{ll}
\hline ARTICLE INFO & $\begin{array}{l}\text { ABSTRACT } \\
\text { Received: 24 Feb. 2020 }\end{array} \quad \begin{array}{l}\text { The purpose of this text is to map knowledge conveyed at the discipline of Methodology of Mathematical Sciences } \\
\text { at Escola Normal Superior of Coimbra that began functioning in 1912 until 1930. Firstly, requirements for } \\
\text { admission to the school are addressed; secondly, a description of the first year disciplines, the pedagogical } \\
\text { practice of the second year, and the final exam is included; and thirdly, the discipline General Methodology of } \\
\text { Mathematical Sciences in the ENS of Coimbra will be addressed through an account of its teachers and its } \\
\text { didactical procedures. }\end{array}$
\end{tabular}

Keywords: history of mathematics education, pedagogical content knowledge, teacher education

\section{INTRODUCTION}

From the last decades of the nineteen century, a movement for the professionalization of Portuguese secondary teachers gained ground aiming for the creation of specific courses giving access to teaching positions at secondary schools. The 1895 reform that provided the roots for contemporary secondary school system required a well-prepared set of professionals. Although primary school teachers (for 6 to 10 years-old) were already required to have a specialized formation, in secondary education teaching candidates should only pass examinations for which a university education was not necessary and that situation was no longer acceptable.

In 1901 a Secondary Teaching Formation Course of four years (Curso de Habilitação para o Magistério Secundário) was created. This training model required future teachers to obtain the scientific training at the university level during the first three years and, in the fourth, a pedagogical training took place in Lisbon.

The model was further developed after the implantation of the Republic in 1910 with the creation in 1911 of two Escolas Normais Superiores (Higher Normal Schools, ENS in short) attached to the Faculties of Letters of Coimbra and Lisbon, which were completely functioning in 1915 (Gomes, 1989). These ENS represent, from 1915, a significant step in the development of teachers' professional knowledge and consequent establishment of autonomy of school knowledge in Portuguese secondary education. For the first time, contexts for reflections and practices focusing on specific contents of school mathematics and the related teaching methods were being pursued at an academic level.

Born out of the republican desire to value education, these schools intended to give the dignity of a higher degree to professional teacher education and played a central role in the formation of professionals to teach mathematics in secondary schools (Matos, 2014). Later, the dictatorial regime created by Oliveira Salazar (1926-1974) would take a set of measures that led to their extinction in 1930.

The ENS were initially studied by Joaquim Ferreira Gomes (1989) who presented an exhaustive survey of documentation concerning the two schools, in particular the one from Coimbra. A more analytical approach was developed by Joaquim Pintassilgo, Maria João Mogarro and Raquel Henriques (2010) who related legislative pieces and other documentation to the movements of pedagogical thought of the time. Mogarro (2012) also studied the relations between the formation in the ENS and the New School trend and António Ferreira and Luís Mota (2013) analyzed the course disciplines.

This movement gathers a cluster of ideas disseminated from the end of the eighteenth century that essentially put the student at the centre of the educational process. It aims to base teaching and learning in children's experiences and values the importance of active methods rejecting authoritarian pedagogical approaches centred on the transmission of abstract knowledge. The proposals of Jean-Jacques Rousseau, Johann Heinrich Pestalozzi, among others, are associated with this movement. 
The purpose of this text is to map knowledge conveyed at the discipline of Methodology of Mathematical Sciences at Escola Normal Superior of Coimbra that began functioning in 1912. This paper is based on documentation preserved at the archives of the University of Coimbra, at personal archives, and in Biblioteca Nacional in Lisbon that was not previously studied, as far as mathematics education is concerned. Previous work on this topic from our research at Universidade Nova de Lisboa focused on the development of mathematics teachers' professional knowledge (Matos, 2017), on the ENS's role in the circulation of ideas (Santiago \& Matos, 2018), and norms and practices at these schools (Santiago \& Matos, 2019). A comprehensive study on the subject was published (Santiago \& Matos, 2018).

Firstly, I will address the requirements for admission to the school, in particular, its entrance examinations; secondly, I will describe the first year disciplines, the pedagogical practice of the second year, and the final exam; and thirdly, the discipline General Methodology of Mathematical Sciences in the ENS of Coimbra will be addressed through an account of its teachers and its didactical procedures.

\section{ENTRANCE EXAMINATIONS}

To be admitted to the ENS, prospective secondary teachers should have had a college degree and have passed an entrance examination. In the case of mathematics, candidates should have had at least a "Bacharelato" in mathematics ( 3 years). This degree had a roughly similar structure at the University of Coimbra and at the two polytechnic schools of Lisbon and Porto (Santiago \& Matos, 2019). It included the following disciplines:

- Higher Algebra, Analytic Geometry, Spherical Trigonometry

- Differential, Integral, and Variations Calculus, Probability,

- Rational Mechanics,

- Descriptive Geometry,

- Astronomy, Geodesy,

- Physics, Chemistry, Mineralogy, Geology, Zoology, Botanic,

- Drawing.

Entrance examinations were composed of two parts. An eliminatory general part, common to all prospective teachers, intended to verify the degree of general culture of the candidates. It was composed of a written essay about Portuguese history (3 hours) and a translation of a text from Portuguese to French (1 hour). These examinations also included a special part akin to the discipline the candidates intended to teach. In the case of mathematics, this part was composed of a practical test, which involved solving a problem of algebra or geometry and two oral examinations on analysis and geometry. Candidates could also present other elements they have written (books, texts...) and some in fact wrote special 'mémoires' for the exam on such topics as set theory, conics, complex numbers, and complex functions (Santiago \& Matos, 2019).

The archives keep some of the written tests including students' answers. Examinations for the special part in mathematics that were found included problems of geometry, analytic geometry, analysis, algebra, and numerical computations with a difficulty level near to the one they had experienced at the Bacharelato. We present some of them below.

Discuss the curve represented by the equation $y=x^{3}-2 x^{2}+3 x+1$ and show the form of the curve. (Entrance examination, Special part, 7/12/1917)

Given the equation of the ellipse $y^{2}-3 x y+5 x^{2}+2 y-3 x-5=0$, determine the diameter of the cords parallel to the line $y=2 x-1$ and the curve's axes. (Entrance examination, Special part, 26/1/1918) ${ }^{1}$

Calculate with the support of logarithmic tables the expression

$$
\frac{4.5832}{\sqrt[5]{28 \sin 24^{\circ} 15^{\prime} 8 \prime \prime}}: \frac{\sqrt[3]{\pi}}{e}
$$

(Entrance examination, Special part, 20/3/1920)

A folder of documents was found (Box 1) that allows us to understand the procedures for the entrance examinations of the special part of mathematics for the school year 1925-26. Although the school year should have started in October, these exams only took place between 23/11/1925 and 12/12/1925 and the jury convened several times to prepare lists of problems and questions that were later distributed among the candidates. Classes for the first year must have taken place between January and June of 1926.

One handwritten document lists the problems of analysis and algebra that were given in the afternoon of 2/12/1925. These included properties of polynomials and proofs involving series and integrals which the candidates had two hours to complete. Below are two examples of these questions:

If $P$ and $Q$ are two relatively prime polynomials, having degrees $m$ and $n$ respectively, there are two other polynomials $P_{1}$ and $Q_{1}$, of degrees $m_{1}<m$ and $n_{1}<n$, such that

\footnotetext{
${ }^{1}$ Diameter of the cords may refer to the family of cords parallel to the given line.
} 
$P Q_{1}+P_{1} Q=1$.

The system $P_{1}, Q_{1}$ is unique.

(Entrance examination, analysis part, 2/12/1925)

Any fraction smaller than the unity can be univocally developed in a series of the form $\frac{1}{2^{\alpha 1}}+\frac{1}{2^{\alpha 2}}+\cdots+\frac{1}{2^{\alpha n}}+\cdots$ with different integer numbers $a_{n}$.

Prove this proposition and deduce a rule to approximately evaluate the side of the regular pentagon, using only the subdivision of segments in 2 equal parts.

(Entrance examination, analysis part, 2/12/1925)

A typewritten document listing the distinct geometrical problems proposed to the candidates in the afternoon of 3/12/1925 was also found containing problems of descriptive, projective, and analytic geometry. Candidates had two hours to solve one of these. Below are two examples.

[Trace perpendiculars from one point to two straight lines.] Find the nature of the locus of the points such that the distance between the intersecting points of the perpendiculars to the straight lines is constant.

(Entrance examination, geometry part, 3/12/1925)

Show that, if an angle of fixed size is moving on a plane, such that the vertex describes a fixed straight line and a side passes a fixed point, the other side has a parabola as its envelope.

(Entrance examination, geometry part, 3/12/1925)

Another typewritten document lists the questions posed at the oral examinations of 1925, which took place after the written parts was found. It includes the following topics: analytical study of conics with centre; analytical study of the circle and its relationship with conics; homogeneous coordinates in the plane and "in the star" , transformation formulas of these coordinates; polarity in the fundamental forms of the second kind, applications to the study of conics; classification and diametric properties of quadrics; tangent planes to the revolution surfaces by the methods of descriptive geometry. In the middle of December the process was concluded. For example, in 1915 all four candidates passed the test but their final grades (in the scale 0-20, in which a grade below 10 means a failure) were not high. We are aware of 47 prospective secondary mathematics teachers that passed these exams but we do not have information of how many candidates failed the tests. Apparently, even if these tasks included standard problems studied at the universities, which we did not verify, the examiners intended to check mathematical knowledge of the candidates beyond an elementary level.

\section{THE DISCIPLINES OF THE FIRST YEAR}

After entrance, students attended a two-year course that included an initiation to pedagogical practice in the secondary schools (Liceus) (Santiago \& Matos, 2018). Given the shortage of teachers in some areas, it is likely that some of the candidates already had teaching experience.

The curriculum of the first year was composed of the following disciplines: Pedagogy (with exercises in experimental pedagogy) (annually), History of Pedagogy (annually), Child Psychology (semesterly), Theory of Science (semesterly), Organization and Comparative Legislation of Secondary Education (quarterly), General Hygiene and especially School Hygiene (semesterly), Moral and Higher Civic Instruction (semesterly). ${ }^{3}$

It also included three disciplines of methodology: General Methodology of Mathematical Sciences, General Methodology of Life Sciences, and General Methodology of Sciences of the Spirit that students should attend in line with their prospective teaching discipline. For example, prospective teachers of Mathematics and Physics and Chemistry should attend the first.

This curricular plan valued the general and specific pedagogical training on the basis of the assumption that education and psychology are experimental sciences. Hygiene and moral education, the topics dear to the republican spirit of the time, were also included; the latter was considered an important element of instruction of republicans and secular citizens (Pintassilgo, Mogarro, \& Henriques, 2010). The General Methodologies were new because they focused on the specific professional knowledge of each

\footnotetext{
2 May refer to coordinates used in cosmography.

${ }^{3}$ The curricular plan underwent minor changes three years after schools started, abolishing the Theory of Science, dividing the discipline of Legislation in two semesters and creating a discipline of General Methodology of the Sciences of the Spirit (Decree $n^{\circ} 4,649$, Diário do Governo, 157, 1918, pp. 1311-4).
} 
school discipline. The discipline General Methodology of Mathematical Sciences is the focus of this article and is discussed in the next section.

Legislation included recommended teaching methods for the ENS. The instruction was supposed to include magisterial lessons, conferences followed by discussions or sets of practical assignments, especially written exercises to be done in class, exercises on experimental pedagogy, and experimental studies of children's pedagogy.

The disciplines of Pedagogy and Psychology in the ENS of Coimbra were taught essentially by Augusto Joaquim Alves dos Santos (1866-1924) until his death and later by José Joaquim de Oliveira Guimarães (1877-1960). The former was a pioneer of Experimental Psychology in Portugal. A colleague of Édouard Claparède at the Jean-Jacques Rousseau Institute in Geneva, he created the first laboratory in this area in the country and was well acquainted with the leading European psychologists of his day.

The discipline of Pedagogy contained what was believed to be the core of knowledge related to education: its foundations, curricular organization, and teaching methods (Pintassilgo, Mogarro, \& Henriques, 2010). Between 1917 and 1930, topics of students' written essays and conferences encompassed themes such as measurement of memory and auditory attention, ludic activities, psychological conditions of attention, pedagogical optics. Most notably, some of these essays report exercises of experimental pedagogy. For example, the essay Measurement of auditory attention written in 1917 by Francisco Ferreira Neves (Box 1) describes how he measured reaction times of blindfolded "subjects" hearing a series of strokes. He explains how the experiment was designed and reaction times to six series of strokes varying in rhythm (constant/varying) and warning (given or not given prior to the beginning of the experiment) were measured. Distractions were added. Several tables and graphics were included and a descriptive statistical analysis supported the conclusions. After discussing the limitations of the study, he concluded that warnings seemed to shorten reaction times.

Luciano Pereira da Silva (1864-1926), a mathematician, and Joaquim de Carvalho (1892-1958), a philosopher, taught History of Pedagogy in the ENS of Coimbra. Students' essays kept at the archives address topics as History of instruction in Portugal, Religious congregations in the 17th century, The New School, Russian Pedagogy after 1918. The ideas of pedagogues were also discussed, namely: Pestalozzi, Rousseau, Rabelais, Montaigne, João de Barros. In a given school year, the same topic was assigned to all students in the class.

There are differences in style among these disciplines. Firstly, an enthusiastic teacher of Psychology, sought to introduce students to the ways in which a scientific (experimental) methodology could be used in an innovative field. Secondly, this perspective allows for the discipline of Pedagogy to have a very advanced status, which in fact did, as we can see by the modernity of the references used. Thirdly, the contents of the discipline History of Pedagogy were different from the scientific interests of the teachers in charge, but we will see how its teachers may have given it a perspective akin to their own research preferences.

\section{THE SECOND YEAR, PEDAGOGICAL PRACTICE}

Under the legislation, the second year was occupied by an initiation to the pedagogical practice developed at the Liceus accompanied by an adviser, a secondary school teacher (Santiago \& Matos, 2018). Until December candidates had to assist to the classes of their advisers and teach occasionally. The advisers also had to teach them the special methodology of the discipline. During the rest of the year, candidates would have full teaching responsibilities supervised by their advisers and had to participate in other school activities. University professors were also supposed to participate in these educational activities but it is unclear if they ever did.

In Coimbra, pedagogical practice was conducted at Liceu José Falcão and Alberto Álvaro Dias Pereira (1891-1984) was the adviser for most of the time. He was a former teacher of mathematics in several schools, a congressman, and also the Rector of the Liceu. He was dismissed as a teacher for political reasons in 1936. Occasionally other teachers took this role: António Tomé e Aníbal do Amaral Cabral, José Custódio de Morais.

In Lisbon the pedagogical practice was conducted in three Liceus and the advisers were: Adolfo Bernardino de Sena Marques e Cunha (1872-1927) at Liceu Pedro Nunes (he had a background in medicine and was a prominent member of a religious group); Domitila Hormizinda de Carvalho (1871-1966) at the female Liceu Maria Pia who graduated in mathematics and philosophy, and had a doctorate in medicine (she was the first woman to officially graduate in the University of Coimbra and one of the first women deputy at the national assembly); and José Ferreira de Carvalho e Santos at Liceu Passos Manuel.

We do not have much information about the actual procedures of the pedagogical practice (class attendance, interactions between advisor and students, etc.), nor do we have any evidence that university teachers participated in the activities of the second year. We only know that prospective teachers took the classes of the advisors and their attendance was monthly reported to the ENS, and, at least from 1927, students were required to write their teaching plans for specific topics.

\section{THE DISSERTATIONS AND THE FINAL EXAM}

After finishing the pedagogical practice of the second year of the course, a State Examination [Exame de Estado] took place and the jury appreciated the overall merit of the candidate's work. The exam included: two discussions of half an hour each, a lesson given to a class in the Liceu followed by its pedagogical discussion, and the presentation of a dissertation on a topic of didactics of secondary teaching at the candidate's choice. This dissertation together with the performance during the teacher practice were significant elements for passing this Examination. From 1927 the dissertation was replaced by a report on the pedagogical practice. 
Joaquim Ferreira Gomes found the titles of numerous dissertations (1989), essentially produced by ENS students from Coimbra. This listing was enriched with other titles we collected through the consultation of legislative acts, personal archives, and documentation in Biblioteca Nacional in Lisbon.

We are currently familiar with the titles of 42 dissertations related to the teaching of mathematics at ENS in Coimbra - which correspond to almost all of those presented in State Examinations - and two from ENS in Lisbon that were studied in Santiago and Matos (2018). As might be expected, two-thirds of the papers indicate the development of topics in school mathematics (The Teaching of Derivatives in Liceus or On Extending the Idea of Number, for example). Some remaining titles study topics such as trigonometry, logarithms, complex numbers, indeterminate analysis or numerical approximations. Most of the rest are titles of a general scope (Mathematics in secondary education, etc.).

\section{THE DISCIPLINE METHODOLOGY OF MATHEMATICAL SCIENCES}

The discipline Methodology of Mathematical Sciences in ENS of Coimbra is the focus of this article. Although the ENS were only fully operative in 1915, this discipline actually started functioning in 1912 when the first teachers were appointed and the first students were admitted (Gomes, 1987). The reason for this early start is given in the corresponding legislative pieces and occurs because there were prospective teachers that were finishing the old Curso de Habilitação para o Magistério Secundário created in 1905 that wanted to joint the new schools.

\section{The Teachers of the Discipline at ENS of Coimbra}

The teaching staff of the first year disciplines of the ENS was made up of professors from the Faculties of Letters and Sciences of the Universities of Lisbon and Coimbra which accumulated the regency of their seats with the regency of the subjects of the Escola Normal Superior. This option rendered easier and, in particular, less expensive, to train this group of teachers. However, it also meant that the institutions never really had its own teaching staff, which, associated with the fact that it also did not have a space, will certainly have had negative consequences in terms of building a school culture and institutional identity.

The teacher of the discipline in the ENS of Lisbon was Eduardo Ismael dos Santos Andrea (1879-1937). He taught at several liceus in the country, was a Professor at the Polytechnic School of Lisbon and Director of the Normal School of Lisbon. Politically involved, Andrea also left its mark in the problems of teaching mathematics and published several textbooks for secondary education. It is unfortunate that the archives did not yet produce any material related to his teachings.

The Methodology of Mathematical Sciences in the ENS of Coimbra was taught by three teachers (Matos, 2018). The first, José Bruno de Cabedo de Almeida de Azevedo e Lencastre (1860-1922), was nominated in January of 1912 when ENS was still in its beginnings and requested his exoneration in February of the same year. He was a professor of Differential Calculus (1885-1901), Higher Analysis (1902-1910), Drawing (1906-1909), Analysis and Geometry (1911-1922), and Differential and Integral Calculus (1917-1918) at the University of Coimbra. His short tenure did not allow him to leave a mark on the discipline.

The succeeding professor, Luciano Pereira da Silva, lectured between March 1912 until his sudden death in 1926. Between these two dates he was occasionally replaced by his colleague, João Pereira Silva Dias (1894-1960).

Luciano was a professor of Differential and Integral Calculus (1902-1904), Celestial Mechanics (1904-1911, 1916-1922), Descriptive Geometry (1910-1911), Mechanics and Astronomy (1911-1922), and Rational Mechanics (1917-1922) at the University of Coimbra. He was also an astronomer at the University Observatory and the first Director of ENS of Coimbra until his death in 1926.

He is mainly known as a prominent author of books about history of mathematics, astronomy, and navigation. He developed the first systematic presentation of nautical knowledge practiced by Portuguese navigators between 1450 and 1550 and his work decisively contributed to the emergence of a flow of studies on a subject hitherto practically ignored. He oversaw the publication of early Portuguese works on astronomy and navigation of the fifteen and sixteen centuries together with an analysis of mathematical and astronomical knowledge incorporated in the main literary work of the sixteen century in Portuguese, the poem Os Lusíadas written by Luís de Camões (1524?-1579?) and finished probably in 1556.

He had a close association with Joaquim de Carvalho (1892-1958), who would became a major scholar in Portuguese history and a precursor of Cultural History, with whom he taught History of Pedagogy. Still as a young professor, Carvalho assumed the post of director of the University press in 1921, and was director of the general library of the University of Coimbra between 1927 and 1931, positions from which he was removed for political reasons. He was one of the most eminent figures of Portuguese culture in the first half of the 20th century, with a vast work published and recognized internationally and an important civic intervention. His complete work was collected in nine volumes and in them his writings on philosophy and history of philosophy, history of culture and literary criticism, history of science, political thought, writings on the University of Coimbra and philosophical essays stand out. He was an eminent figure in the renewal of the history of culture.

However, despite his vast work, he does not dwell on what we today, more strictly, call the history of education. This appears only in its relationship with Portuguese thought and culture and never in an autonomous way. He was not a historian of education or pedagogy, in the current and strict sense with which the term is used today. Focusing of researching culture, he promoted the publication of hundreds of books, many dealing with the critical edition of sources and documents, and encouraged several lines of research, in particular in the history of science and about Portuguese thinkers.

The published correspondence between Luciano Pereira da Silva and Joaquim de Carvalho (Barbosa, 1984) reveals the degree of collaboration between the two close friends at a time when Luciano was painstakingly reconstructing a chronology of 
Portuguese materials on navigation techniques of the sixteen century and Joaquim, almost thirty years younger, was beginning his search for a history of thought from the same epoch.

Luciano had also a close, although more distant, relationship with Jaime Cortesão (1884-1960), a respected politician and historian, that, among other endeavours, shared his interest in Portuguese expansion during the sixteen century. Cortesão designated the other two as the "library group", a reference presumably to the prominent role both played in the publication of documents pertaining to the Portuguese culture by the University Press.

The third professor of the discipline was João Pereira Silva Dias (1894-1960), a teacher of Analysis and Geometry (1914-1917, 1918-1923), Projective Geometry (1917-1918, 1923-1924), Descriptive Geometry (1923-1924, 1932-1933), Mathematical Physics (1923-1924), Higher Geometry (1932-1933), and Calculus (1932-1933). He enrolled as a student in the University in 1911. His high grades weren't unnoticed and he was invited to take teaching position while he was still a student:

"Pereira Dias, at the age of eighteen, had teaching functions at the Faculty as Assistant of Descriptive Geometry in collaboration with Ferreira da Silva; he was in charge of the Luciano Pereira da Silva' chair. He had done excellent tests in the first year of the University (1911-1912), especially in this discipline of Geometry, so favourable to the flowering of his natural aptitudes for Drawing. In April 1913 he was already an Assistant.” (Esparteiro, in Simões \& Tenreiro, 2013, p. 196)

In 1913 and 1914 he and Pereira da Silva were involved in the creation of a Cabinet of Geometry for which they purchased several models (Simões \& Tenreiro, 2013).

As for his duties at ENS, for several years he replaced Luciano Silva in the latter General Methodology teaching classes, as confirmed by the former signature in students' tests or homework even when Luciano was registered as the teacher. Much later he was appointed Director of the Faculty of Sciences (1939-1959) and during this tenure he was chosen for official positions related to education and culture. One of his students (Simões-Pereira, 2012) called him "a quiet man", determined to maintain the quality of the Faculty the difficult years during and following the Second World War.

João Dias did not write texts about education and Luciano Silva did not write any publication related to education specifically related to his activity as a teacher in ENS. We are only aware of a speech he gave in Parliament in 1903, discussing the 1894 Reform. In it he shows that he is very familiar with teacher education in Germany, France, England, and the United States of America. He defends the German model, even though he considers aspects from other countries, paying attention to the pedagogical, theoretical and practical preparation of teachers, and he defended that the mathematics faculty could do all the qualification of mathematics teachers for high schools, dealing with pedagogy applied to your specialty.

In the preface of Astronomia dos Lusíadas, however, he expands some of his views on teaching methods:

"Modern pedagogists understand that the student must follow, in its general lines, the same path that Humanity followed in the elaboration of any science. Instead of being a passive recipient of theories already made, he should be led to take the attitude of an active researcher, interested in observing phenomena well and formulating natural laws himself. It is the process of rediscovery. Thus, in astronomy, direct observation of celestial phenomena will lead you first to the Ptolemaic conception. The Copernican conception will follow naturally.

The direct research method, called "laboratory method", stirs interest and enthusiasm, which are difficult to obtain by other means. There is no need for an observatory equipped with good telescopes. Just a place with unobstructed views. It begins with observation with a unhindered sight, made with elementary instruments, built in the locality, or in the workshops of educational establishments, if any. The astrolabe is naturally indicated. (...) That's why I explain the construction of the wooden astrolabes that were on our ships. The problems that worried our navigators are a good exercise. At first, students make simple observations. Thus they learn to see and gain, first hand, a good amount of astronomical knowledge, which reveals to them the fundamental principles of the movements of the stars. And reading the astronomical passages of 'Os Lusíadas will be a strong stimulus in a teaching conducted in this way." (Silva, 1972, pp. 5-6)

He supports his perspective on a book by Mary Byrd (A Laboratory Manual in Astronomy, Boston, 1899). Following this passage, we can frame him in a "heuristic" current, related to the very genesis of scientific knowledge defended by him and Joaquim de Carvalho. Other teachers at the school, namely Eusébio Tamagnini (1880-1972) - professor of General Methodologies of Natural Sciences, Director of the ENS of Coimbra after Luciano's death in 1926 and later Minister of Public Education between 1934 and 1936 - , and Oliveira Guimarães (1877-1960) - professor of General Methodologies of Sciences of the Spirit - placed more emphasis on the rigor of the knowledge transmitted.

\section{The Practices of the Discipline at the ENS of Coimbra}

Previously, in order to establish the constitution of mathematics teachers' professional knowledge, we studied the final dissertations of aspiring teachers (Santiago \& Matos, 2018, 2019). Physically, these are texts between 20 and 110 pages of various sizes, some printed in book printing shops, others typewritten. Apparently prospective teachers chose the topic with a reasonable degree of freedom and were given some time, occasionally over a year, to write these texts. In none of the texts do we find a reference to either a professor of the ENS or their adviser at the Liceu and students assumed their choice of the theme, sometimes showing a strong conviction about its importance. So, we can assume they "own" the opinions expressed in the dissertations, which were thoroughly thought about. 
The students' documents generated by the classroom activities, however, were written much nearer to actual teaching events and, especially the written exercises in class, are, in that sense, "raw" materials much influenced by the professors' perspectives which means that through them we can have a closer look at teaching contents.

We begin by trying to establish how the classroom activities unfolded through the school year, and for that purpose we will look into two documents from the school year 1925/26. The first, a schedule of the course's first year that distributes classes along the days of the week, indicating their beginning time along with the teacher responsible for each discipline. From it we learn that classes run from Monday afternoon through Saturday with no classes in Wednesday's afternoon. Prospective mathematics teachers had classes Mondays', Wednesdays', and Thursdays' afternoons, and Tuesdays' and Fridays' all day. The General Methodology of Mathematical Sciences met Tuesdays and Thursdays at 15 o'clock and the teacher was Luciano Pereira da Silva. There is no information about class time. However, if we compare it with the discipline Methodology of Sciences of Nature, we may infer that classes run for one hour and a half or two hours maximum.

The second source is a typewritten document authored by the "Bedel" (an administrative employee overseeing bureaucratic tasks related to class daily life) detailing each student's activities. The document does not contain summaries for the lessons and lists only activities that produce consequences for the evaluation of students. This source, composed with other documents at the archives, allows us to map some classroom events.

That school year the class was composed of six students (Mário Rego Costa, Luís de Castro Marques, Manuel Augusto Rabaça, and Mário Santos Guerra, prospective teachers of mathematics; Irene Pissara Cabral prospective teacher of Physics and Chemistry and Manuel Fernandes de Carvalho probably another prospective teacher of Physics and Chemistry).

In that year, classes may have started in January of 1926 or later as we have seen previously in the discussion of entrance examination. In the 4th of March there was the first evaluation activity, a written exercise in class about "Synthetic and analytical methods, induction and deduction". A student, Carvalho, may have missed this class and in the 15th of March was asked to write a different exercise on "Reduction and deduction". Also in March an oral exercise took place of which we do not know the details. Two conferences were scheduled to the 25th of May, an oral exercise to the 8 th of June, and a written exercise in class to the 11 th of June. None of these activities apparently took place as students were on a national strike that, in the case of the University of Coimbra, started in the 24th of May and ended in the middle of June.

Although in this particular year most of the scheduled activities did not occur, the document written by the "Bedel" in December of 1926 (probably to document the disruption caused by the student's strike and support decisions about conclusion of the course) allows us to understand what could be the usual sequence of class activities and make sense of existing documents from other years.

The archives contain several documents related to the discipline from 1916 until 1930, mostly written essays from the students. As required by the legislation, these essays were of several kinds:

1) Written essays (take home assignments) about the following topics: "Laboratory methods (1917, 1920, 1923), "The value of graphs in the laboratory method" (1921), "Inductive and deductive method" (1923), "Specific methods of mathematical sciences" $(1924,1930))$.

2) Written exercises (in class assignments) comprising the topics: "Laboratory method" (1917, 1918, and many other years), "Graphic method" (1921), "Induction and deduction (1923), "Analytical method" (1924), "Synthetic and analytical methods, induction and deduction" (1926).

3) Conferences by students. Apparently one student each year was chosen to prepare a conference an another was selected to write a report of the conference and its discussion. We found the following themes: "Inductive and deductive method" (1920), "Methods of mathematical sciences" (1921, 1924), "Graphic method" (1923), "Laboratory method" (1930).

We must note that this are traces of the discipline based on what we found in the archives. Some years are missing, for example, we do not have materials from the years 1915/16, 1916/17, 1918/19, 1921/22, 1926/27, and 1927/28 (six out of fifteen years) and for some other years we could only find a limited number of documents. But even with this limitation it was possible to draw some hypothesis, namely that students' evaluation focus on two main topics: laboratory method and methods for the mathematical science.

The "closer look" to classroom events endowed by the written exercises in class can be appreciated in an exercise that took place in 29/6/1918 on the topic "Laboratory method". The two pages essay by António Augusto Riley da Mota (1893-1967) ${ }^{4}$ a prospective science secondary teacher, begins with the following words:

"Perry in England and Moore in the United States of America were the spokespeople for the movement that had long been drawn against the dogmatic, dry, and abstract teaching of mathematics, replacing [it by] what has come to be called the laboratory method.

This one sacrifices the meticulous rigor to the interest; impeccable precision and perfection to an assimilable and attractive way of explaining; extreme logic to psychology data.

The touchstone used to assess the qualities of a pedagogical exhibition is the interest, not that of the teacher but that of the student." (Box 1, underlines in the original)

\footnotetext{
${ }^{4}$ At the time Riley da Mota was a teaching assistent of Physics and Chemistry disciplines ate the Unversity. He later became a teacher and Rector at a Liceu. During the first half of the 1940s he was Diretor Geral do Ensino Liceal.
} 
Mota continues by arguing that the method advocates for closer links between mathematics and the other sciences. The method links mathematics to its historical roots and the psychological science. The other essays on the topic present similar ideas.

As we have seen, the laboratory method is espoused by Luciano Pereira da Silva and we have here a perspective of how it may have been communicated ipsis verbi in class. One of the main defenders of the laboratory approach is John Perry (1850-1920), Irish engineer and applied mathematician. According to Perry, the usual mathematical education did not take into account the minds of children, their interests, the applications of mathematics and connections between different areas of mathematics. His idea of practical mathematics applied to the study of geometry meant that the first job with geometry was to involve students using rulers, compasses, compasses, squares and scissors. Perry proposed math labs in which problem-based approaches incorporated technological developments associated with graphical analysis and the use of slide rules. He proposed the regular use of graph paper, in which the integrating element would be the concept of function (Furinguetti, Matos, \& Menghini, 2013).

The topic of the 1918 exercise is not an isolated event and the laboratory method is the theme of many assignments. In fact, this topic is present in all school years for which we have documents except in the a-typical year 1925/26, either as a class exercise or a take home. For example, in 1917, by the end of May, a written exercise on "The laboratory method" was proposed to the class, probably as a take-home exam. The three handwritten essays of this year in the archives (ranging from 4 to 16 pages) focused on the contemporaneous trends in school education in England and the United States, on how a logical approach to mathematics was being changed to a method grounded in Psychology and taking into account children's interest (today we would say 'motivation'). Very similarly to Mota's essay, all supported the importance of planning mathematical instruction as a move from the concrete to the abstract and stressed the importance of linking together distinct mathematical topics and of integration of mathematics with other subjects.

Take home exercises, do not have the spontaneity of in-class exercises, still they do provide an opportunity to appreciate a more reflected approach as students probably had one or two months to prepare. Looking at these essays on the laboratory method, we see the development of the ideas already expressed in the examples above.

Assigning its birth to the proposals of John Perry, Eliakim Hastings Moore (1862-1932), and Jacob William Albert Young (18651948), they all argue that it represents a departure from an approach to mathematics based on logic and abstraction in favour of a consideration of students' interest which, as psychology and pedagogy argue, lies in moving from concrete to abstract. Moreover, the laboratory approach to mathematics teaching should foster interdisciplinary approaches to the discipline and allow for closer interactions between the teacher and individual students.

In the essays, the laboratory method is sometimes associated with the production of graphics. The take home test handed over by seven students in November of 1921, when João Pereira Dias was called to temporarily replace Luciano Pereira da Silva, proposed the topic "The Value of Graphics in the Laboratory Method". Apolinário José Leal's answer, a prospective teacher of Physics and Chemistry, for example, after referring the birth of the "Perry movement" in England and the United States, crudely states that "the processes that this new method uses are: the correlation of subjects and the march of teaching from concrete to abstract, albeit with the sacrifice of logic" (Box 1). He continues by arguing that "graphs are easily assimilated by children who are thus made to become familiar with the relationships between geometry and calculus". Graphic representations are common:

"The use of curves to represent variations in temperature, price, production, population, etc. is often used by newspapers and magazines as a means of more easily and quickly showing their readers the variations suffered by the values of a certain quantity, merchandise, etc." (Box 1)

He ends by stressing the importance of graph paper and pencils of several colours in higher grades as a means to make clear the relationships among several variables. The other students express similar points of view, and some include examples of graphical representations of physical phenomena drawn in graph paper glued to the pages.

Of special importance is the text by José de Andrade Novais, a prospective mathematics teacher because, contrary to the majority of the essays written by students, he discusses texts of several authors, namely Claparède, Laisant, and Montaigne.

Some texts list the instruments that should be present in a mathematical laboratory: black boards with and without square grids, compasses, rulers, dihedrals, trihedrals, geometric solids, physics instruments like scales, levers, optical instruments, etc. The graphics approach to mathematics, in particular, is intertwined with this method. The exploration of mathematical topics using graph paper is addressed in several papers as an example of the application of the method to more advanced secondary classes.

Occasionally new proof methods are advocated as a way to substantiate an alternative from logic in the educational setting: 1) proof by measurement, for example determining the ratio of the diameter of a circle to its circumference; 2) proof by superposition, in which figures are cut and superposed to show they are equal; 3) proof by movement, as angles of a triangle are moved to successive vertices to show they add up to 180 degrees; 4) proof by inspection, when a mere inspection of a mathematical object provides the answer.

Another topic that can be found in the assignments is an exploration of mathematical methods. Virtually all assignments written on this subject classify mathematical methods into all or some of the following types: analytical (or deductive), synthetic, reduction to the absurd, and infinitely small (or exhaustion, or the limits). For example, Armando das Neves Learcher, a prospective teacher of Historical and Natural Sciences, in his assignment turned the 26/5/1924 explains how the analytic method proceeds: "a series of propositions is established, starting with the one we want to prove and ending with a known, proved proposition, such that each one is a necessary consequence of the one that follows, with the result that the first will be a consequence of the latter and therefore true as it is" (Box 1). He shows how this method can be used to prove the formula for the area of a rectangle. The synthetic method: "consists of starting from true recognized propositions, deriving from them others, as necessary consequences, 
and from them [derive] new propositions and so on" (Box 1) and he applies it to prove a theorem on angles in a composition of two parallel lines cut by an intersecting line. Similarly he presents the reduction to the absurd method and proves the theorem that given two parallel lines, a perpendicular to one of them is perpendicular to the other. He then proceeds to explain the exhaustion method, which "consists in demonstrating an equality in which quantities that are limits of others enter, applying the method of reduction to the absurd" (Box 1). This method is appropriate to deal with infinitesimal or infinitely large quantities. He uses it to show that the squares of the radii of two circles are proportional to their surface area. Two other methods described in the dissertations (Santiago \& Matos, 2019), inductive, indeterminate coefficients, could not be found in these assignments.

\section{CONCLUSION}

ENS schools were intended to replace the system under which access to the position of secondary teachers depended solely on the approval on a state exam. These new schools included demanding entrance requirements both in general knowledge and in mathematical proficiency.

In this text I intend to map knowledge conveyed by the discipline General Methodology of Mathematical Sciences in the ENS of Coimbra. Underneath this objective was the search for the origin of the ideas expressed in the final dissertations of prospective teachers we studied elsewhere (Santiago \& Matos, 2018). Grosso modo, in previous work we found a pervasive presence of ideas stemming from the Comission Internationale de l'Enseignement Mathématique (CIEM), the New School movement, and the utilitarian perspective on education. We also argued that these dissertations constituted the ground for the elaboration of pedagogical content knowledge for secondary school mathematics in Portugal. The study of this discipline could provide a finer account of how the ideas expressed in these dissertations came about.

So, to map knowledge conveyed by the discipline, firstly, I looked at the teachers of the discipline where Luciano Pereira da Silva's ideas seem to be the towering influence over the discipline General Methodology of Mathematical Sciences at the ENS of Coimbra. A trained mathematician and an accomplished historian of navigation, he brought with him an appreciation of the heuristic dimension of mathematical thought that he translated to the "laboratory method" he so keenly taught in the 14 years of his tenure. João Pereira Dias, his successor, just followed the steps of his mentor.

Secondly, I looked at the practices and when we look at the documents from the daily life of the discipline General Methodology of Mathematical Sciences at ENS of Coimbra, we encouter a more limited perspective than the one found in the dissertations. The pervasiveness of appraisal of the laboratory approach with its emphasis on the predominance of the concrete over the intangible, of the intuition over the logic, of the applications of mathematics over the abstract resonate very well to the kind of arguments more thoroughly espoused in the dissertations and can be traced back to the enthusiasm Perry's ideas received elsewhere (Furinghetti, Matos, \& Menghini, 2013).

Moreover, the proposals of the New School movement underlay many documents studied here. In Portugal, this perspective was widely spread from the end of the nineteenth century as Education (or Pedagogy) and Psychology started seeking acceptance as scientific fields. The republican movement used the New School banner ("intuitive teaching") as a perspective that would improve schools (Mogarro, 2012). In the documents studied, the ideas from this movement are essentially associated with the laboratory method and its emphasis on students' motivation and on concrete approaches to mathematics teaching, although in the dissertations these arguments are more deeply presented, usually grounded in psychology or education thinkers.

Some dissertations discuss the same mathematical methods we found in the texts but elaborate further, supporting their reflections on the nature of mathematics on a broad range of authors, none of which can be found in the documents studied here. For example, the importance of intuition in mathematics is not discussed, although this theme is extensively present in the dissertations, usually associated with Poincaré's proposals.

Finally, discussions related to specific mathematics topics, usually stimulated by the CIEM (innovations in geometry and analysis, for example), present in many dissertations, are absent in the documents studied here.

As a global appreciation, it is possible to state that the learning experience at the discipline is at the root of many ideas expressed later in the dissertations. However, the source of other ideas must be looked elsewhere, namely in the other disciplines and in prospective teachers independent study of materials about teaching and learning mathematics.

\section{REFERENCES}

Aires, A. P., \& Santiago, A. (2014). Os programas de Matemática do Ensino Liceal em Portugal. In A. J. Almeida, \& J. M. Matos (Eds.), A matemática nos programas do ensino não-superior (1835-1974) (pp. 71-91). Lisbon: APM.

Barbin, É., \& Menghini, M. (2014). History of Teaching Geometry. In A. Karp \& G. Schubring (Eds.), Handbook on the History of Mathematics Education (pp. 473-492). London: Springer. https://doi.org/10.1007/978-1-4614-9155-2_23

Barbosa, J. (1984). Correspondência de Luciano Pereira da Silva para Joaquim de Carvalho. Separata do Boletim Bibliográfico da Universidade de Coimbra, 39(1984), 41-90. Coimbra: Coimbra Editora.

Box 1: Depósito IV, Secção $2^{\mathrm{a}}$.E, Estante 9, Tabela 5, $\mathrm{n}^{\circ}$ 19. Escola Normal Superior de Coimbra. Arquives of the University of Coimbra. (Archive of the University of Coimbra)

Box 2: Depósito IV, Secção $2^{\mathrm{a}}$.E, Estante 9, Tabela 5, $\mathrm{n}^{\circ}$ 21. Escola Normal Superior de Coimbra. Arquives of the University of Coimbra. (Archive of the University of Coimbra) 
Ferreira, A. G., \& Mota, L. (2013). A formação de professores do ensino liceal. A ENS da Universidade de Coimbra (1911-1930). Revista Portuguesa de Educação, 26(2), 85-109. https://doi.org/10.21814/rpe.3247

Furinghetti, F., Matos, J. M., \& Menghini, M. (2013). From mathematics and education, to mathematics education. In A. B. M. Clements, C. Keitel, J. Kilpatrick, \& F. Leung (Ed.), Third International Handbook of Mathematics Education (pp. 273-302). London: Springer. https://doi.org/10.1007/978-1-4614-4684-2_9

Gomes, J. (1989). A Escola Normal Superior da Universidade de Coimbra (1911-1930). Lisbon: IIE.

Howson, A. G. (1984). Seventy five years of the International Commission on Mathematical Instruction. Educational Studies in Mathematics, 11, 75-93. https://doi.org/10.1007/BF00380440

Julia, D. (1995). La culture scolaire comme objet historique. Paedagogica Historica. International Journal of the History of Education, 31(sup. 1), 353-382. https://doi.org/10.1080/00309230.1995.11434853

Mogarro, M. J. (2012). República e Ensino Normal: sob o signo da pedagogia da Escola Nova. In A. Adão, C. Silva, \& J. Pintassilgo (Eds.), O Homem vale, sobretudo, pela educação que possui: Revisitando a primeira reforma republicana do ensino infantil, primário e normal (pp. 45-59). Lisbon: IEUL.

Pintassilgo, J., Mogarro, M. J., \& Henriques, R. (2010). A formação de professores em Portugal. Lisbon: Colibri.

Santiago, A. \& Matos, J. M. (2018). A matemática e o seu ensino nas Escolas Normais Superiores. In J. M. Matos (Ed.), A matemática e o seu ensino na formação de professores. Uma abordagem histórica (pp. 227-256). Lisboa: APM e UIED.

Santiago, A., \& Matos, J. M. (2019). Norms and practices of secondary teachers' formation. The Portuguese case (1915-1930). In F. F. K. Bjarnadóttir, A. Karp, J. Prytz, G. Schubring (Ed.), Proceedings of the Fifth International Conference on the History of Mathematics Education (pp. 339-356). Nieuwerkerk aan den IJssel: Drukkerij Baas.

Silva, L. P. (1972). A astronomia de Os Lusíadas. Lisbon: Junta de Investigações do Ultramar.

Simões, C., \& Tenreiro, C. (2013). O Gabinete de Geometria da Faculdade de Ciências e a sua colecção de modelos para o ensino. In C. Fiolhais, C. Simões, \& D. Martins (Eds.), História da ciência na Universidade de Coimbra: 1772-1933 (pp. 193-207). Coimbra: Imprensa da Universidade. https://doi.org/10.14195/978-989-26-0610-1_7

Zuccheri, L., \& Zudini, V. (2014). History of Teaching Calculus. In A. Karp \& G. Schubring (Eds.), Handbook on the History of Mathematics Education (pp. 493-513). London: Springer. https://doi.org/10.1007/978-1-4614-9155-2_24 